\title{
Effects of short term beta adrenoreceptor blockade on serum lipids and lipoproteins in patients with hypertension or coronary artery disease
}

\author{
M B MURPHY, D SUGRUE, „ I TRAYNER, S KAUFMAN, H YASUHARA,† C T DOLLERY, \\ G R THOMPSON
}

From the Departments of Clinical Pharmacology, Cardiology, and Chemical Pathology, Royal Postgraduate Medical School; and the Medical Research Council Lipoprotein Team, Hammersmith Hospital, London

SUMMARY The effects of beta adrenoceptor blockade with propranolol or pindolol on serum total cholesterol, low density lipoprotein cholesterol (LDL), high density lipoprotein cholesterol (HDL), and its subfractions $\mathrm{HDL}_{2}$ and $\mathrm{HDL}_{3}$, serum triglyceride, and Intralipid clearance were studied in 17 normolipidaemic, non-diabetic patients with hypertension or angina pectoris. Both pindolol and propranolol had similar effects on fasting serum total and lipoprotein cholesterol concentrations. $\mathrm{HDL}_{2}$ cholesterol concentrations were reduced by $9 \pm 29 \%$ and $\mathrm{HDL}_{3}$ cholesterol increased by $11 \pm 16 \%$, but there were no significant changes in total or LDL cholesterol in the combined groups after six weeks' treatment. After 12 weeks' treatment total cholesterol concentrations were reduced by $7 \pm 10 \%$ mainly owing to a reduction in the LDL fraction of $9 \pm 15 \%$. Concentrations of $\mathrm{HDL}_{2}$ remained low, $8 \%$ less than control values. Serum triglyceride concentrations were increased by both drugs at six weeks but had returned to base values in the pindolol group by the twelfth week. Pindolol, but not propranolol, enhanced the rate of clearance of intravenous Intralipid.

The failure to show a reduction in coronary artery morbidity in several large studies of antihypertensive treatment ${ }^{1-3}$ has raised the possibility that the metabolic side effects of the drugs used could negate the benefits of blood pressure reduction. Diuretics, the most widely used agents, promote glucose intolerance $^{4}$ and hypokalaemia ${ }^{5}$ and increase serum uric acid $^{6}$ and both serum cholesterol and triglyceride concentrations. ${ }^{7}$ Although beta receptor blockers have not been studied as extensively, they have been reported to raise serum concentrations of triglycerides ${ }^{8-10}$ and to reduce those of high density lipoprotein cholesterol, ${ }^{9-11}$ effects which may theoretically increase the risk of coronary artery disease. ${ }^{12} 13$ Since these drugs are now prescribed for life in young patients with mild hypertension, even small alterations in these cardiovascular risk factors could

Requests for reprints to Dr M B Murphy, Department of Clinical Pharmacology, Royal Postgraduate Medical School, Hammersmith Hospital, Ducane Road, London W12 0HS.

*Present address: Department of Cardiology, The Mayo Clinic, Rochester, Minnesota, USA.

†Present address: Department of Pharmacology, School of Medicine, Showa University, Tokyo, Japan.

Accepted for publication 26 January 1984 have adverse consequences in the long term. Even though only controlled prospective studies can test this hypothesis, it would seem prudent to use only those drugs with the fewest effects on lipoprotein metabolism.

Since the initial report that long term treatment with propranolol increased serum triglycerides and decreased serum free fatty acids, ${ }^{8}$ there have been numerous studies of the effects of beta blockers on serum lipid fractions. Differences in the drugs studied and the doses used, the inclusion of patients with hyperlipidaemia, the concurrent use of other drugs, and variation in the duration of treatment have, however, led to conflicting and confusing results (for review see Johnson. ${ }^{14}$ ) In addition, none has examined the effects of beta blockade on high density lipoprotein (HDL) cholesterol subfractions, one of which $\left(\mathrm{HDL}_{2}\right)$ is emerging as an even better predictor of coronary artery disease than total or HDL cholesterol. ${ }^{15}$

In this study we examined the effects of beta blockade acutely and during three months' treatment in patients with hypertension or angina pectoris who were otherwise healthy and untreated. Since some earlier studies suggested that drugs possessing partial 
agonist or intrinsic sympathomimetic activity might have smaller effects on serum lipids ${ }^{16-18}$ we compared the effects of two beta receptor blocking drugs, propranolol and pindolol, only one of which, pindolol, has partial agonist activity.

\section{Patients and methods}

Twenty two patients with mild essential hypertension or symptomatic coronary heart disease consented to participate in the study. Patients with known diabetes mellitus, hyperlipidaemia, asthma, hepatic or renal impairement, or other serious systemic disease were excluded. After five weeks taking a placebo the patients were investigated after an overnight fast. Weight, height, blood pressure, and peak expiratory flow rate were measured. A 19 gauge butterfly needle was inserted in an antecubital vein on each forearm and patency maintained with sodium citrate. A $20 \mathrm{ml}$ blood sample was drawn for measurement of serum triglyceride, total cholesterol, and HDL cholesterol concentrations. An intravenous fat tolerance test was then performed. Intralipid (Kabi Vitrum) 10\% (1 $\mathrm{ml} / \mathrm{kg}$ ) was infused during one minute, and $5 \mathrm{ml}$ blood samples were drawn from the opposite cannula at 5 minute intervals for the next 30 minutes. The patients continued to take a placebo for a further week, after which they were randomly assigned to receive propranolol $160 \mathrm{mg}$ or pindolol $10 \mathrm{mg}$ twice daily in a double blind fashion. They underwent further tests, identical to those with the placebo, two hours after the first dose of the beta receptor blocking agent and again after six and 12 weeks of treatment. They were requested not to alter their dietary, smoking, or drinking habits for the duration of the study.

Serum triglyceride concentrations were measured by an enzymatic method using a Technicon autoanalyser (method No SE4-0039 PE6). To measure the HDL cholesterol, low density lipoprotein (LDL) and very low density lipoprotein cholesterol (VLDL) were first precipitated in an aliquot of serum using heparin and manganese chloride. ${ }^{19}$ One aliquot of the supernatant was used for cholesterol analysis, while dextran sulphate was added to another to precipitate the $\mathrm{HDL}_{2}$ fraction. ${ }^{20}$ The cholesterol content of the resulting supernatant, comprising the $\mathrm{HDL}_{3}$ fraction, was then determined. $\mathrm{HDL}_{2}$ cholesterol was derived by calculating the difference between the total HDL and the $\mathrm{HDL}_{3}$ cholesterol concentrations. Cholesterol was measured by an enzymatic method using the Technicon autoanalyser (Method No SE4-0065 FB1). LDL cholesterol was calculated by the method of Friedewald et al. ${ }^{21}$ Serum opalescence after Intralipid administration was measured by spectrophotometry. 22

All patients gave informed consent and the protocol was approved by the research ethics committee of these institutions. Results are expressed as means \pm standard deviation. Paired $t$ tests were used to compare within treatment data and unpaired tests to compare the effects of the two drugs. Linear regression analysis was used to correlate variables.

\section{Results}

Seventeen of the 22 patients completed the study. Of the remainder, one was withdrawn because of nightmares and another because of poor blood pressure control requiring additional treatment and three withdrew for personal reasons. The pretreatment characteristics of those who completed the study are listed in Table 1. There were no significant differences between the two treatment groups in age, weight, or pretreatment blood pressure. Both had similar concentrations of total cholesterol, LDL, $\mathrm{HDL}$, and $\mathrm{HDL}_{2}: \mathrm{HDL}_{3}$ ratios before treatment (Table 2). Those treated with pindolol, however, had significantly lower triglyceride clearance rates and paradoxically lower serum triglyceride concentrations than those treated with propranolol.

Table 1 Characteristics of patients treated with either propranolol or pindolol. Values are means $\pm S D$

\begin{tabular}{lll}
\hline & Propranolol & Pindolol \\
\hline No of patients & 9 & 8 \\
Age (yr) & $46 \pm 12$ & $43 \pm 13$ \\
Sex $(\mathrm{M} / \mathrm{F})$ & $6 / 3$ & $7 / 1$ \\
Weight (kg) & $73 \cdot 7 \pm 18 \cdot 1$ & $78 \cdot 2 \pm 12 \cdot 2$ \\
Blood pressure (mm Hg) & $148 \pm 17 / 96 \pm 7$ & $138 \pm 18 / 96 \pm 12$ \\
\hline
\end{tabular}

Since pindolol and propranolol had similar effects on serum total and lipoprotein cholesterol throughout the study (Fig. 1) the cholesterol data of the combined groups are reported. Total serum cholesterol was unchanged at the sixth week but was reduced by $7 \pm 10 \%(p<0.01)$ at the twelfth week of treatment, mainly owing to a reduction of $9 \pm 15 \%$ in the LDL fraction (Fig. 2). Although there was a small but significant increase in HDL cholesterol concentration after the first dose the values at six and 12 weeks were similar to those after placebo. Despite this stability of HDL cholesterol during long term treatment there were significant changes in its constituent subfractions. $\mathrm{HDL}_{2}$ cholesterol was reduced by $9 \pm 23 \%$ $(p<0.05)$ at six weeks and remained low at 12 weeks. On the other hand $\mathrm{HDL}_{3}$ was increased at six weeks $(11 \pm 16 \%, p<0.05)$, but this increase had disappeared by 12 weeks. Thus at six weeks $\mathrm{HDL}_{2}$ carried only $31 \pm 12 \%$ of the cholesterol in HDL in contrast to $36 \pm 13 \%(p<0.02)$ before beta receptor blockade, and the ratio of $\mathrm{HDL}_{2}$ to $\mathrm{HDL}_{3}$ was reduced from $0.63 \pm 0.34$ to $0.5 \pm 0.25(\mathrm{p}<0.02)$.

The initial changes in serum triglyceride concentrations were minimal after both drugs (Fig. 2), but at 
Table 2 Effects of beta blocking agents on serum lipid concentrations (mmol/l) in patients treated with either propranolol ( $n=9)$ or pindolol $(n=8)$. Values are means $\pm S D$

\begin{tabular}{|c|c|c|c|c|c|c|c|c|}
\hline & \multicolumn{4}{|l|}{ Propranolol } & \multicolumn{4}{|l|}{ Pindolol } \\
\hline & Basal & First dose & 6 weeks & 12 weeks & Basal & First dose & 6 weeks & 12 weeks \\
\hline $\begin{array}{l}\text { Serum cholesterol } \\
\text { concentration } \\
\text { Total } \\
\text { LDL } \\
\text { HDL } \\
\mathrm{HDL} \\
\mathrm{HDL} \\
\mathrm{HDL} /{ }_{\text {total HDL }} \\
\mathrm{HDL} / \mathrm{HDL}_{3}\end{array}$ & $\begin{array}{l}6.04 \pm 0.99 \\
4.35 \pm 0.87 \\
1.4 \pm 0.37 \\
0.55 \pm 0.34 \\
0.85 \pm 0.13 \\
0.32 \pm 0.11 \\
0.65 \pm 0.40\end{array}$ & $\begin{array}{l}6.04 \pm 1.18 \\
4.23 \pm 1.09 \\
1.54 \pm 0.35 \\
0.62 \pm 0.33 \\
0.92 \pm 0.16 \\
0.37 \pm 0.14 \\
0.70 \pm 0.37\end{array}$ & $\begin{array}{l}6.20 \pm 1.18 \\
4.45 \pm 1.15 \\
1.44 \pm 0.42 \\
0.48 \pm 0.29 \\
0.96 \pm 0.22 \\
0.32 \pm 0.13 \\
0.51 \pm 0.27\end{array}$ & $\begin{array}{l}5.66^{\star \star} \pm 0.86 \\
3.98^{\star \star} \pm 0.81 \\
1.37 \pm 0.30 \\
0.46 \pm 0.18 \\
0.90 \pm 0.20 \\
0.33 \pm 0.10 \\
0.53 \pm 0.23\end{array}$ & $\begin{array}{l}5.30 \pm 0.54 \\
3.81 \pm 0.61 \\
1.29 \pm 0.39 \\
0.49 \pm 0.26 \\
0.80 \pm 0.18 \\
0.34 \pm 0.14 \\
0.61 \pm 0.26\end{array}$ & $\begin{array}{l}4.99 \pm 0.46 \\
3.40 \pm 0.51 \\
1.36 \pm 0.40 \\
0.48 \pm 0.26 \\
0.88 \pm 0.21 \\
0.39 \pm 0.17 \\
0.55 \pm 0.29\end{array}$ & $\begin{array}{l}5.48 \pm 0.77 \\
3.92 \pm 0.66 \\
1.30 \pm 0.39 \\
0.44 \pm 0.27 \\
0.87 \pm 0.17 \\
0.33 \pm 0.12 \\
0.49 \pm 0.25\end{array}$ & $\begin{array}{l}4.83 \pm 0.61 \\
3.40 \pm 0.52 \\
1.23 \pm 0.33 \\
0.46 \pm 0.31 \\
0.77 \pm 0.19 \\
0.35 \pm 0.11 \\
0.64 \pm 0.45\end{array}$ \\
\hline $\begin{array}{l}\text { Triglyceride } \\
\text { concentrations } \\
\text { Triglyceride } \\
\text { clearance }(\% / \mathrm{min})\end{array}$ & $\begin{array}{l}1.45 \pm 0.97 \\
5.3 \pm 1.9\end{array}$ & $\begin{array}{l}1.33 \pm 0.83 \\
5.5 \pm 2.1\end{array}$ & $\begin{array}{l}1.59 \pm 0.87 \\
5.7 \pm 2.8\end{array}$ & $\begin{array}{l}1.56 \pm 0.84 \\
4.4 \pm 1.4\end{array}$ & $\begin{array}{l}1.03 \pm 0.48 \\
2.9 \pm 1.7\end{array}$ & $\begin{array}{l}1 \cdot 10 \pm 0.52 \\
4 \cdot 4 \pm 3 \cdot 4\end{array}$ & $\begin{array}{l}1.27 \pm 0.99 \\
3.9 \star \pm 1.2\end{array}$ & $\begin{array}{l}0.96 \pm 0.31 \\
4.5 \pm 2.6\end{array}$ \\
\hline
\end{tabular}

${ }^{\star} \mathrm{p}<0.05 ;{ }^{\star \star} \mathrm{p}<0.01$.

HDL, high density lipoprotein; LDL, low density lipoprotein.

six weeks they had increased by $21 \pm 39 \%(p<0 \cdot 1)$ in the combined groups (Fig. 1). By the twelfth week, however, they had returned to baseline values in the pindolol group, although they remained raised in those treated with propranolol (Table 2). Whereas the rate of clearance of infused triglycerides was not altered by propranolol it was significantly enhanced in

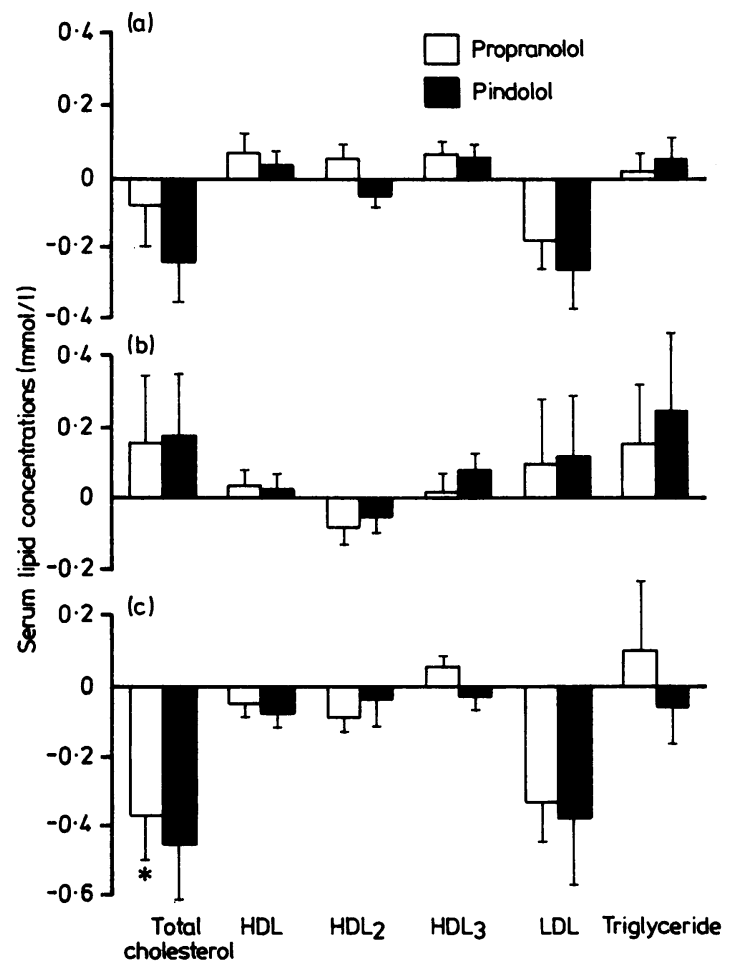

Fig. 1 Changes in serum lipid concentrations after (a) the first dose and (b) six and (c) 12 weeks' treatment with propranolol $(n=9)$ and pindolol $(n=8)$. Values are means $\pm S E M$. $H D L$, high density lipoprotein; $L D L$, low density lipoprotein.

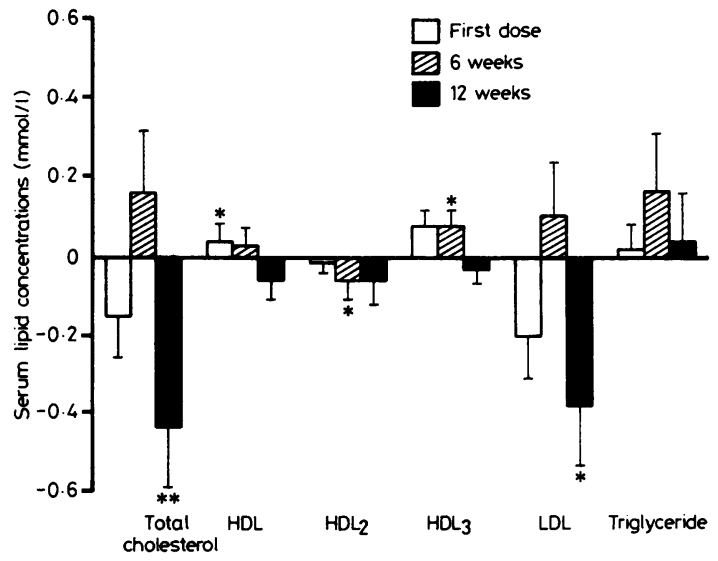

Fig. 2 Changes in serum lipid concentrations after the first dose of beta receptor blocking agent and after six weeks' and 12 weeks' treatment with pindolol or propranolol $(n=17)$. Values are means $\pm S E M .{ }^{\star} p<0.05 ;{ }^{\star \star} p<0.01 . H D L$, high density lipoprotein; $L D L$, low density lipoprotein.

those treated with pindolol: this latter group had slower fractional clearance rates initially, but these rose during treatment from $2.9 \pm 1 \cdot 7$ to $3.9 \pm 1 \cdot 2 \% / \mathrm{min}$ after six weeks $(\mathrm{p}<0.03)$ and to $4.5 \pm 2.6 \% / \mathrm{min}$ after 12 weeks (Table 2). There was, however, no correlation between changes in serum triglyceride concentrations and in Intralipid clearance rates. Whereas basal serum triglyceride correlated negatively both with HDL $(r=-0.63, p<0.01)$ and $\mathrm{HDL}_{2}(r=-0.71$, $p<0.01$ ), there were no correlations between the changes in triglyceride concentrations and in HDL or $\mathrm{HDL}_{2}$ at six weeks $(\mathrm{r}=-0.049$ and -0.185 respectively) or at 12 weeks $(r=-0.173$ and -0.138 respectively).

The effects of both drugs on blood pressure and heart rate are shown in Fig. 3. Whereas propranolol caused a significant bradycardia (from $77 \pm 11$ to $57 \pm 7$ 


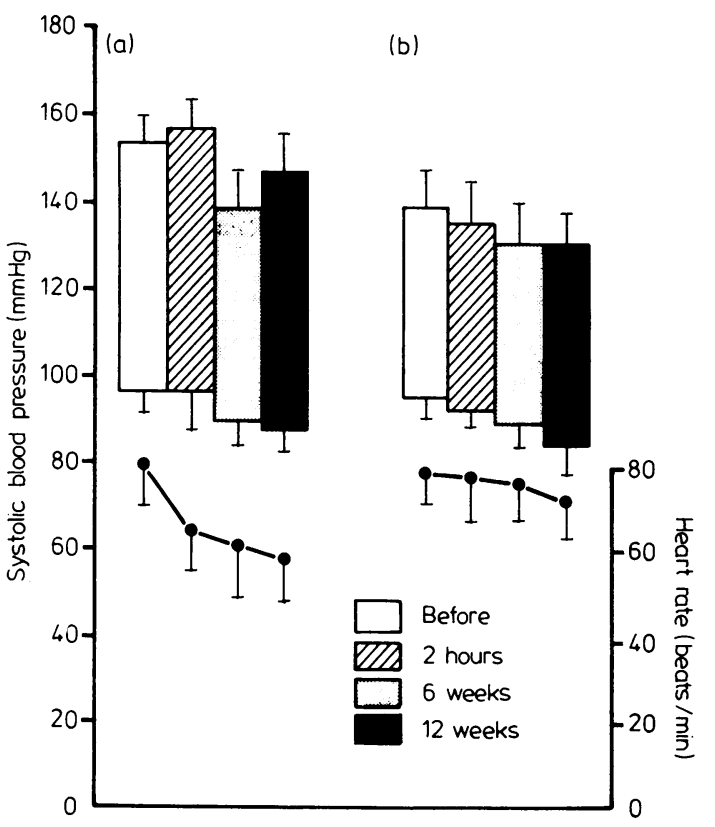

Fig. 3 Blood pressure and heart rate before and two hours after the first dose and after six and 12 weeks' treatment with (a) propranolol $(n=9)$ and $(b)$ pindolol $(n=8)$. Values are means $\pm S E M$.

beats/min at 12 weeks) the reduction in resting heart rate after pindolol (from $77 \pm 13$ to $69 \pm 6$ beats $/ \mathrm{min}$ ) was considerably less. Neither drug affected peak expiratory flow rate, and there were no significant changes in body weight in either group.

\section{Discussion}

In this study significant changes occurred in serum lipid concentrations during three months' beta adrenoceptor blockade. Whereas some changes were already known (the increase in serum triglyceride and reduction in cholesterol concentrations), this is the first report that beta adrenergic blocking agents may influence HDL subfractions. Both propranolol and pindolol caused similar changes in fasting total and HDL cholesterol concentrations, but pindolol, unlike propranolol, accelerated triglyceride clearance. Although the numbers of patients studied were small and caution is needed when interpreting differences between the two drugs, it is unlikely that partial agonist activity substantially influences the response of serum lipid concentrations to beta receptor blockade in normolipidaemic subjects.

Early work on the metabolic effects of hypotensive drugs was confined to examining changes in serum total cholesterol and triglyceride concentrations, but more recent studies have focussed on changes in HDL cholesterol concentration since this correlates strongly and inversely with the risk of vascular disease. Most workers, but not all, 23-25 have found a reduction in HDL cholesterol with beta receptor blockers. Although HDL cholesterol remained unchanged in our patients there was a significant reduction in its quantitatively minor subfraction $\mathrm{HDL}_{2}$. The latter, rather than total HDL, has the strongest negative correlation with the extent of coronary artery disease in angiographic studies. ${ }^{15} \mathrm{HDL}_{2}$ cholesterol is present in higher concentrations in women, ${ }^{26}$ who have a lower prevalence of vascular disease than men, and is increased by moderate alcohol intake ${ }^{27}$ and exercise, ${ }^{28}$ which may protect against vascular disease. Conversely, smoking restricts the normal postprandial increase in $\mathrm{HDL}_{2}$ cholesterol. ${ }^{29}$ In contrast to the reduction in $\mathrm{HDL}_{2}$ cholesterol we also found a potentially beneficial reduction in LDL cholesterol, whose concentration correlates positively with the presence of vascular disease. ${ }^{13}$ This decrease was slower in onset than that of $\mathrm{HDL}_{2}$, since it was not evident at the sixth week, but in percentage terms was comparable iri extent. Similar reductions have been reported previously after propranolol ${ }^{81023}$ and acebutolol. ${ }^{23}$ Whereas considerable prognostic importance has been attributed to the reduction in HDL cholesterol by beta blocking agents, less attention has been given to their ability to reduce LDL, which could theoretically offset the former's effects.

The initial increase in serum triglyceride concentrations confirms the findings of most previous studies ${ }^{14}$; longer term studies have shown that these increases in response to beta blockade tend to persist. WaalManning reported a continuing increase in triglyceride concentration after one year's treatment with metoprolol, ${ }^{30}$ whereas Schulman et al found raised values after one year in patients taking propranolol in the BHAT trial. ${ }^{31}$ The present study confirmed the persisting increase in triglyceride concentrations after three months' treatment with propranolol but not with pindolol: indeed this was the only noticeable difference between the two drugs, although poor matching of the groups with respect to pretreatment Intralipid clearance and fasting triglyceride concentrations limits interpretation of its clinical significance. Nevertheless, the similarities in the triglyceride response to pindolol in this study and in the Oslo trial, ${ }^{16}$ in which there was a small, albeit statistically non-significant, increase at six weeks and decrease at 10 weeks, suggest that the acute and long term effects of this beta receptor blocking agent may differ.

A primary aim of this study was to clarify the mechanism by which beta adrenoceptor blockade alters serum lipid concentrations. The proposal that 
the effects were mediated through inhibition of lipoprotein lipase in vascular endothelium ${ }^{32}$ was of particular interest since it would explain not only the increase in triglyceride concentrations but also the reductions in $\mathrm{HDL}_{2}$ and LDL cholesterol seen in this study. VLDL catabolism by lipoprotein lipase in adipose and muscle tissue results in the formation of LDL and in the release of surface components which contribute to the conversion of $\mathrm{HDL}_{3}$ to $\mathrm{HDL}_{2} \cdot{ }^{33}$ Unlike Day et $a l,{ }^{32}$ however, we found no reduction in Intralipid clearance, an index of lipoprotein lipase activity, in our patients during beta receptor blockade. The increase in triglyceride concentration in the propranolol group was not accompanied by a decrease in the rate of Intralipid clearance, whereas the small increase in triglyceride at six weeks in the pindolol group occurred despite appreciable acceleration of the clearance of Intralipid. Furthermore, whereas there were significant inverse relations between basal triglyceride, $\mathrm{HDL}$ cholesterol, and $\mathrm{HDL}_{2}$ cholesterol concentrations in the whole group, changes in these indices did not correlate, as would be expected if lipoprotein lipase were inhibited by beta receptor blockade. This, coupled with the evidence that lipoprotein lipase activity in adipose tissue biopsy specimens from patients treated with propranolol is increased, ${ }^{34}$ suggests that beta receptor blockade may promote triglyceride synthesis rather than inhibit its catabolism.

In conclusion, the serum cholesterol changes in this study were small and their long term prognostic significance uncertain. Reduction in $\mathrm{HDL}_{2}$ cholesterol concentrations may be detrimental, but the concomitant reduction in LDL could offset this. Similarly, small increases in triglyceride concentrations by themselves are unlikely to contribute to vascular morbidity. ${ }^{35}$ The mechanism of changes in serum lipids induced by beta blocking agents remains unclear in that we found no evidence that triglyceride clearance was inhibited by propranolol, although it was apparently improved by pindolol.

\section{References}

1 Helgeland A. Treatment of mild hypertension: a five year controlled drug trial. The Oslo Study. Am F Med 1980; 69: 725-32.

2 Hypertension Detection and Follow-up Program Cooperative Group. Five year findings of the Hypertension Detection and Follow-up Program: I. Reduction in mortality of persons with high blood pressure, including mild hypertension. FAMA 1979; 242: 2562-71.

3 National Heart Foundation of Australia. Management Committee. The Australian therapeutic trial in mild hypertension. Lancet 1980; i: 1261-7.

4 Murphy MB, Lewis PJ, Kohner E, Schumer B, Dollery CT. Glucose intolerance in hypertensive patients treated with diuretics: a fourteen-year follow-up. Lancet; 1982; ii: $1293-5$.

5 Bulpitt CJ. Serum uric acid in hypertensive patients. $\mathrm{Br}$ Heart f 1975; 37: 1210-5.

6 Edmonds CJ, Jasani B. Total-body potassium in hypertensive patients during prolonged diuretic therapy. Lancet 1972; ii: 8-12.

7 Schoenfeld MR, Goldberger E. Hypercholesterolemia induced by thiazides. A pilot study. Current Therapeutic Research 1964; 6: 180-4.

8 Tanaka N, Sakaguchi S, Oshige K, Niimura T, Kanehisa T. Effect of chronic administration of propranolol on lipoprotein composition. Metabolism 1976; 25: 1071-5.

9 Leren P, Helgeland A, Holme I, Foss PO, Hjermann I, Lund-Larsen PG. Effect of propranolol and prazocin on blood lipids. The Oslo Study. Lancet 1980; ii: 4-6.

10 Bielmann P, Leduc G, Jequier JC, Davignon J, Cartwright $\mathrm{K}$. Changes in the lipoprotein composition after chronic administration of metoprolol and propranolol in hypertriglyceridaemic, hypertensive subjects. Current Therapeutic Research 1981; 30: 956-67.

11 Helgeland A, Hjermann I, Leren P, Enger S, Holme I. High-density lipoprotein cholesterol and antihypertensive drugs: the Oslo Study. Br Med F 1978; ii: 403.

12 Miller NE, Forde OH, Thelle DS, Mjos OD. The Tromsø Heart-Study. High density lipoprotein and coronary heart-disease: a prospective case-control study. Lancet 1977; i: 965-8.

13 Gordon T, Kannel WB, Castelli WP, Dawber TR. Lipoproteins, cardiovascular disease, and death. The Framingham Study. Arch Intern Med 1981; 141: 112831.

14 Johnson BF. The emerging problem of plasma lipid changes during antihypertensive therapy. $\mathcal{f}$ Cardiovasc Pharmacol 1982; 4 (suppl 2): S213-21.

15 Miller NE, Hammett F, Saltissi S, et al. Relation of angiographically defined coronary artery disease to plasma lipoprotein subfractions and apolipoproteins. $\mathrm{Br}$ Med F 1981; 282: 1741-4.

16 Leren P, Foss OP, Helgeland A, Hjermann I, Holme I. Effects of pindolol and hydrochlorothiazide on blood lipids-The Oslo Study. Clinical Trials foumal 1981; 18: 254-61.

17 Crisp AJ, Kennedy PGE, Hoffbrand BI, Ebbutt AF, Carruthers M. Lipids and lipoprotein fractions after cyclopenthiazide and oxprenolol: a doubleblind crossover study. Current Med Research and Opinion. 1980; 7: 1013.

18 Shaw J, England JDF, Hua ASP. Beta-blockers and plasma triglycerides [Letter]. $\mathrm{Br} \mathrm{Med} \mathcal{F}$ 1978; i: 986.

19 Warnick GR, Albers JJ. A comprehensive evaluation of the heparin manganese precipitation procedure for estimating high density lipoprotein cholesterol. 7 Lipid Res 1978; 19: 65-76.

20 Khan SR, Elkeles RS, Niththyananthan R, Seed M, Wynn V. Analysis of high density lipoprotein subclasses by a precipitation procedure: comparison with preparative ultracentrifuge. Clin Chim Acta 1982; 120: 49-55.

21 Friedewald WT, Levy RI, Frederickson DS. Estimation of the concentration of low density lipoprotein cholesterol in plasma, without use of the preparative ultracentrifuge. Clin Chem 1972; 18: 499-502. 
22 Zöllner N, Hansen W. A photometric modification of the intravenous fat tolerance test. Atherosclerosis 1972; 15: 345-8.

23 Birnbaum J, DiBianco R, Becker KL, et al. Glucose and lipid metabolism during acetabutolol and propranolol therapy of angina in non diabetic patients. Clin Pharmacol Ther 1983; 33: 294-300.

24 Bauer JH, Brooks CS, Weinstein I, et al. Effects of diuretic and propranolol on plasma lipoprotein lipids. Clin Pharmacol Ther 1981; 30: 35-43.

25 Kristensen BO. Effect of long-term treatment with beta-blocking drugs on plasma lipids and lipoproteins. Br Med f 1981; 283: 191-2.

26 Anderson DW, Nichols AV, Pan SS, Lindgren FT. High density lipoprotein distribution. Resolution and determination of three major components in a normal population sample. Atherosclerosis 1978; 29: 161-79.

27 Taskinen MR, Vảlimäki $M$, Nikkilà EA, Kuusi $T$, Ehnholm C, Ylikari R. High density lipoprotein subfractions and postheparin plasma lipases in alcoholic men before and after ethanol withdrawal. Metabolism 1982; 31: 1168-74.

28 Nye ER, Carlson K. Kirstein P, Rössner S. Changes in high density lipoprotein subfractions and other lipopro- teins by exercise. Clin Chim Acta 1981; 113: 51-7.

29 Elkeles RS, Khan SR, Chowdhury V, Swallow MB. Effects of smoking on oral fat tolerance and high density lipoprotein cholesterol. Clin Sci 1983; 65: 669-72.

30 Waal-Manning $\mathrm{HJ}$. Metabolic effects of $\beta$ adrenoceptor blockers. Drugs 1976; ii (suppl 1): 121-6.

31 Shulman RS, Herbert PN, Capone RJ, et al. Effect of propranolol on blood lipids and lipoproteins in myocardial infarction. Circulation 1983; 67 (suppl 1): 19-21.

32 Day JL, Metcalfe J. Simpson CN. Adrenergic mechanisms in control of plasma lipid concentrations. $\mathrm{Br} \mathrm{Med} \mathcal{F}$ 1982; 284: 1145-8.

33 Patsch JR, Gotto AM Jr, Olivercrona T, Eisenberg S. Formation of high density lipoprotein-like particles during lipolysis of very low density lipoproteins in vitro. Proc Natl Acad Sci USA 1978; 75: 4519-23.

34 Faber G, Berglund G, Bondjers G, et al. Effects of anti- G hypertensive therapy on serum lipoproteins: treatment with metoprolol, propranolol and hydrochlorothiazide. of Artery 1983; 11: 283-96.

35 Hulley SB, Rosenman RH, Bawol RD, Brand RJ. 을 Epidemiology as a guide to clinical decisions. The association between triglyceride and coronary heart disease $N$ Engl f Med 1980; 302: 1383-9. 